\title{
Tuberculum Sellae Meningiomas: Transcranial Approaches Results and Complications
}

\author{
Karam Kenawy, Abdin K. Kasim, Momen M. Almamoun \\ Department of Neurosurgery, Sohag University, Sohag, Egypt \\ Email: abdin_mail@yahoo.com
}

How to cite this paper: Kenawy, K., Kasim, A.K. and Almamoun, M.M. (2022) Tuberculum Sellae Meningiomas: Transcranial Approaches Results and Complications. Open Journal of Modern Neurosurgery, 12, 67-76. https://doi.org/10.4236/ojmn.2022.122007

Received: December 31, 2021

Accepted: March 4, 2022

Published: March 7, 2022

Copyright (c) 2022 by author(s) and Scientific Research Publishing Inc. This work is licensed under the Creative Commons Attribution International License (CC BY 4.0).

http://creativecommons.org/licenses/by/4.0/

(c) (i) Open Access

\begin{abstract}
Objective: Tuberculum sellae meningiomas constitute about 5\% - 10\% of intracranial meningiomas. They are difficult to treat, owing to their close association with the optic nerves, chiasma, and major cerebral arteries. This retrospective study aims to report on the clinical outcome after transcranial approach for treatment of tuberculem sellae meningiomas at our hospital. Patients and Methods: We reviewed patients with tuberculem sellae meningiomas and underwent transcranial surgical approaches for their lesions at Sohag university hospitals over a 4 years period starting from January 2018. The patients' clinical and radiological data, operative details, degrees of tumor removal, outcomes and complications were reported. Results: There were 17 patients with tuberculem sellae meningiomas with a mean age of 46.3 years. Female patients constituted $70 \%$ of cases. Pterional approach was used in 59\% of cases and unilateral subfrontal approach was used in $41 \%$ of cases. Gross total tumor removal was achieved in $82 \%$ of cases. Visual acuity improved in $47 \%$, remained unchanged in $41 \%$, and worsened in $5.9 \%$ of patients. Transient post-operative diabetes inspidus and post-operative haematoma in tumor bed each occurred in 5.9\% of patients. Conclusion: Transcranial removal of tuberculum sellae meningioma is still considered the standard approach, with high rate of gross total resection and better visual outcome and low mortality and morbidity.
\end{abstract}

\section{Keywords}

Tuberculem Sellae Meningioma, Pterional Approach, Skull Base, Outcome, Complications

\section{Introduction}

Tuberculum sellae (TS) meningiomas represent approximately $5 \%$ to $10 \%$ of in- 
tracranial meningiomas [1] [2] [3] [4]. They arise from the tuberculum sellae, chiasmatic sulcus, limbus sphenoidale, and diaphragma sellae and grow in a subchiasmal position. The optic nerves and chiasm may be elevated or displaced laterally with the increasing size of the tumor.

Cushing and Eisenhardt [2] were the first to report 28 cases of meningiomas of the tuberculem sellae and proposed a classification in four stages according to their size. They used the term suprasellar to describe tumors arising from the dura over the tuberculum sellae.

Later, many reports have been published under the classification of suprasellar meningiomas, to describe tumors arising from different locations, including the anterior and posterior clinoid processes, tuberculum sellae, planum sphenoidale, optic foramen, olfactory groove, medial sphenoid ridge, or diaphragma sellae [5]-[18]. Some authors have proposed to distinguish meningiomas of the tuberculum sellae as a separate entity [1] [4] [19]-[24].

As the tumors are located in contact with the optic nerves and the optic chiasm, the aim of surgery is to improve and/or stabilize the visual acuity [25]. The transcranial approach (TCA) has become the standard surgical approach for resection of these tumors, with accepted outcomes, but, with recent advances in endoscopic neurosurgical techniques, the endoscopic endonasal approach (EEA) has been used for its treatment [26]. Other approaches include supraorbital endoscopy, endoscopic-assisted microsurgical techniques.

Many clinical criteria support one surgical approach over another, but the factors affecting the long-term clinical outcomes associated with these approaches remain limited [27]. However, TCA is still considered the gold standard for the resection of TS meningiomas [28]. The transcranial approaches included a variety of craniotomies pterional, unilateral subfrontal, bilateral subfrontal, in an attempt to find the most direct route to this region with the fewest complications or anatomical limitations [3] [4] [15] [20] [29].

As up to $80 \%$ of patients with present with visual deficits, improvement in visual function is main parameter that may be used to assess the Quality of Life (QOL) after surgery [23].

Our objective was to retrospectively review our results using transcranial approach to assess the resection rate, neurological outcome and vision.

\section{Patients and Methods}

We retrospectively reviewed clinical, radiological and operative data of $17 \mathrm{pa}$ tients with tuberculem sellae mengiomas. These patients were operated at our Neurosurgery Department of the Sohag university Hospital from January 2018 to January 2021.

\subsection{Clinical Evaluation}

Preopertive patients' clinical history and neurological examination were reviewed with special attention to data related to pituitary endocrine axis and cranial nerve 
affection and intracranial hypertension.

\subsection{Radiological Evaluation}

All patients underwent CT scan of the brain with and without contrast, magnetic resonance imaging (MRI) brain. Cerebral CT-Angiography in large lesions, were used in some patients for surgical planning.

\subsection{Surgery}

Surgery was performed under general anesthesia using the operating microscope and microsurgical instrumentation in all patients. Tumors were operated via: the pterional and subfrontal approaches.

Pterional approach was chosen with:

- Small lesions

- Large frontal air sinuses

- Suprasellar and/or parasellar extension

- Severe optic nerve compression on one side Subfrontal approach was chosen with:

- Large lesions

- Extension to the planum

- Severe optic nerve compression on both sides

\subsection{Surgical Steps}

A standard pterional approach was used in 10 patients and unilateral subfrontal approach in 7 patients. The surgical techniques were similar to previous descriptions and reports [13] [30]. In both approaches we preferred to operate through the same side of larger tumor extension and/or more manifest optic nerve affection, otherwise, we preferred to operate through the right non dominant side.

Intraoperative and postoperative results and complications were reviewed and analysed. Follw up data in our outpatient clinic for all patients were evaluated and presented.

\section{Results}

Here we present the results of 17 consecutive patients with tuberculem sellae mengiomas operated over the period from January 2017 to January 2021.

\subsection{Age and Sex Incidence}

Out of 17 patients with tuberculem sellae meningiomas: 12 were females $(70 \%)$ and 5 were males (30\%). Age varied from 33 years to 65 years with a mean value of 46.3 years.

\subsection{Clinical Symptoms and Signs: (Table 1)}

The most common symptom was decreased vision and headache (100\%), while the most common sign was bitemporal hemianopia (82\%). 
Table 1. Clinical symptoms and signs.

\begin{tabular}{ccc}
\hline Clinical picture & Number & $\%$ \\
\hline Decreased visual acuity & 17 & $100 \%$ \\
Headache & 17 & $100 \%$ \\
Bitemporal hemianopia & 14 & $82 \%$ \\
Sever visual field defect & 3 & $18 \%$ \\
\hline
\end{tabular}

\subsection{Radiological Findings: (Table 2)}

Suprasellar extension was evident in $82 \%$ of cases while bilateral optic nerve encasement was found in $18 \%$ of cases with the tumor invading the cavernous sinus and encasing anterior cereberal arteries.

\subsection{Operative Data: (Table 3)}

Pterional approach was used in 59\% of cases and Subfrontal approach was used in $41 \%$ of cases.

Extent of tumor resection:

Out of 17 patients gross total resection was achieved in 14 patients (82\%). Residual tumors in the two cases were related to either the carotid artery or anterior cerebral artery that were adherent to these vessels, for which a more aggressive dissection was judged to be injurious. The third case subtotal resection was accepted due to a calcified portion of the lesion extending toward the brainstem, that could not be removed. The dural attachement at the tuberculum sellae and planum sphenoidale was thoroughly coagulated with bipolar cautery in all patients. Histopathologically all tumors were WHO grade I meningiomas.

\subsection{Visual Outcome}

Postoperative visual outcome analysis was performed by ophthalmologist for 16 patients postoperatively. Visual acuity improved in 8 patients (50\%), remained unchanged in 7 patients (43\%), and worsened in one patient (7\%) of patients. One patient died before evaluation of post-operative vision.

\subsection{Complications: (Table 4)}

Post-operative haematoma in tumor bed occurred in 1 patient and was small hematoma and managed conservatively. Another patient developed post-operative transient Diabetes inspidus and treated medically and improved within 1 week of surgery.

Mortality: 1 patient developed post-operative status epilepticus and died in ICU the second day of operation.

\subsection{Case Presentations}

Here we present 2 cases of our series:

The first case was 45 years old female complaining of headache and diminution 
Table 2. Radiological findings.

\begin{tabular}{ccc}
\hline Feature & Number & $\%$ \\
\hline Suprasellar extension & 14 & $82 \%$ \\
Subfrontal extension & 8 & $47 \%$ \\
Bilateral optic nerve compression & 3 & $18 \%$ \\
\hline
\end{tabular}

Table 3. Operative data.

\begin{tabular}{ccc}
\hline Approach & Number & $\%$ \\
\hline Rt Pterional & 7 & $41 \%$ \\
Rt Subfrontal & 4 & $23 \%$ \\
Lt Pterional & 3 & $18 \%$ \\
Lt Subfrontal & 3 & $18 \%$ \\
\hline
\end{tabular}

Table 4. Complications.

\begin{tabular}{ccc}
\hline Complications & Number & $\%$ \\
\hline Postoperative Hge & 1 & $6 \%$ \\
Diabetes Insipidus & 1 & $6 \%$ \\
Death & 1 & $6 \%$ \\
\hline
\end{tabular}

of vision. Clinical and visual field examination showed bitemporal hemianopia and MRI brain showed tuberculem sellae meningioma with suprasellar extension. Figure 1 shows gross total removal via right subfrontal approach.

The second case was 52 years old female presented with headache and diminution of vision. Visual field examination showed bitemporal hemianopia and CT and MRI brain showed tuberculem sellae meningioma with suprasellar extension. Figure 2 shows operative view and postoperative gross total removal via Rt pterional approach.

\section{Discussion}

The tuberculum sellae space, is surrounded laterally by the clinoid processes, internal carotid and posterior communicating arteries with the arachnoid of the carotid cisterns, posteriorly by the pituitary stalk, infundibulum, and Liliequist membrane and superiorly by the optic chiasm, lamina terminalis, and ACA complex [29]. This space is quite small, (mean length $8 \mathrm{~mm}$, mean width $11 \mathrm{~mm}$ ) [13], and the easiest way and the path of least resistance for tumor growth tends to be over the planum sphenoidale anteriorly (possibly due to a defect in arachnoid of the chiasmatic cistern), around the optic nerves sometimes into the optic canals laterally, above the chiasm, displacing it superiorly, and down over the tuberculum sella inferiorly. A layer of arachnoid in most of cases is present between tumor surrounding brain structures, and this provides a plane of dissection. Due to the limits of the tuberculum sellae spaces [29]. 


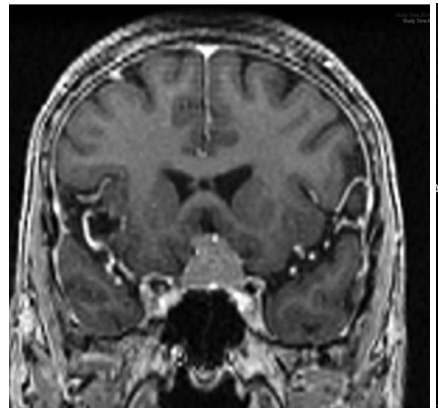

(A)

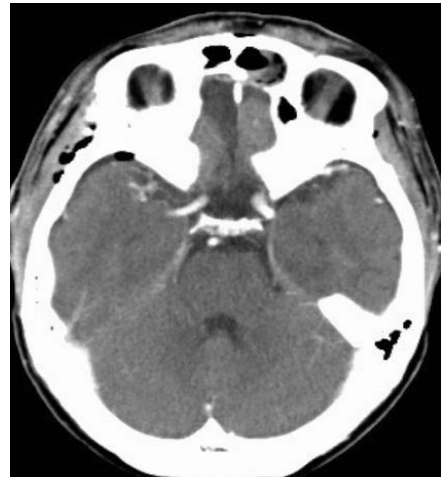

(C)

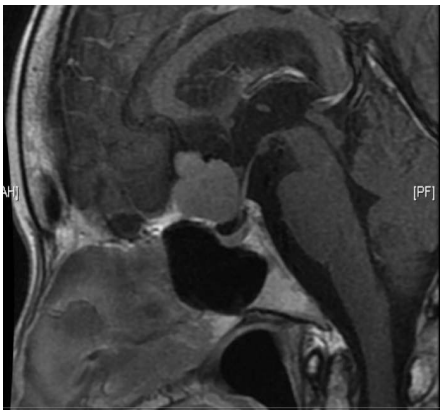

(B)

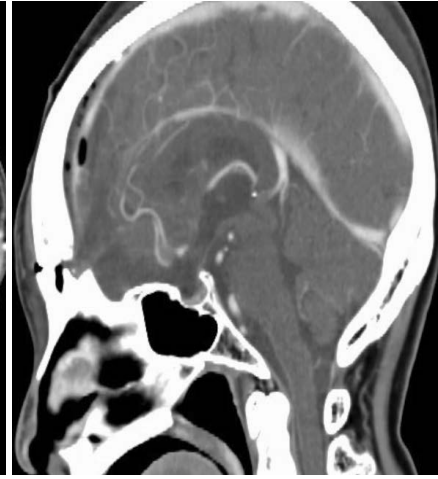

(D)

Figure 1. A case of tuberculem sellae meningioma (A) and (B) preopeartive MRI, (C) and (D) second day postoperative CT showing total removal via Rt subfrontal approach.

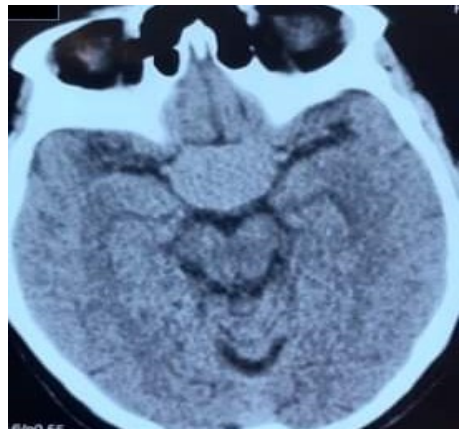

(A)

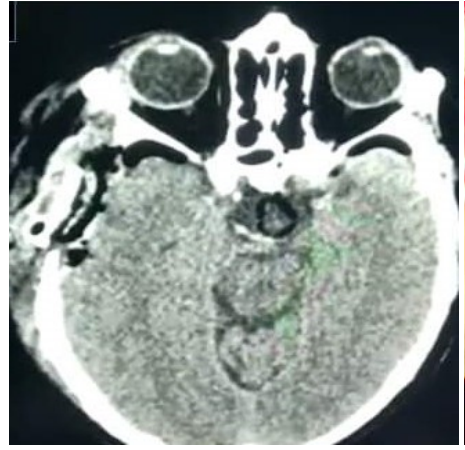

(C)

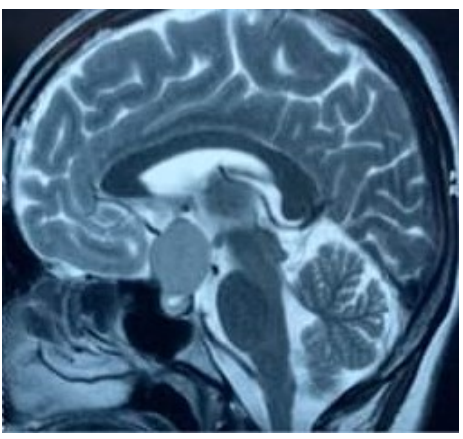

(B)

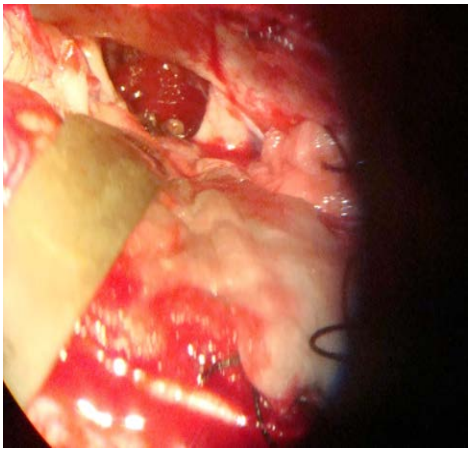

(D)

Figure 2. ((A) and (B) preoperative, (C) 24 hours Postoperative, (D) operative view after tumor excision) showing total resection via Rt pterional approach. 
Due to above mentioned anatomical facts tuberculum sellae meningiomas are difficult to treat, owing to their close association important neurovascular structures. Many approaches were used to address these lesions as unilateral subfrontal, pterional, bilateral subfrontal transbasal interhemispheric approach and recently endoscopic endonasal transsphenoidal approache [13] [26] [30] [31]. In this study pterional approach as used in $82 \%$ of cases and subfrontal approach was used in $18 \%$ of patients.

\subsection{Incidence of Morbidity}

In the literature, the overall morbidity and mortality rate associated with resection of tuberculum sellae meningiomas is quite low [31] [32] [33]. Morbidity has been divided into two types; ophthalmological or non ophthalmological. Causes of non ophthalmological morbidity may require surgical or just medical treatment. Postoperative complications such as cerebrospinal fluid leak (CSF), postoperative hematomas, infections, and psychotic alterations [10]. However in our series Post-operative haematoma occurred in 1 patient (5.9\%) and was small hematoma and managed conservatively and no deterioration occurred for the patient. One patient (5.9\%) developed post-operative transient Diabetes inspidus and improved spontaneously after 1 week of surgery without medication. There were no CSF leak or infection.

\subsection{Incidence of Mortality}

Mortality rates ranging from $0 \%$ in recent series [10] up to $67 \%$ have been reported in old series [10] [28]. Series with no fatalities have been reported during the last two decades with advance of technique and facilities and modern neuroanesthesia [10]. Death has been reported to depend on the size of the tumor [4] [17] [20] [32]. Brihaye and Brihaye-Van Geertruyden [7] reported higher mortality rates in patients with tumors exceeding $3 \mathrm{~cm}$ in diameter $(7.1 \%-44 \%)$. In our series mortality rate is about (5.9\%); there was one male patient who died as he developed post-operative status epilepticus and cardiac arrest.

\subsection{Visual Outcome}

Suprasellar meningiomas usually present with visual deterioration, including decreased visual acuity and/or visual field defects due to affection of the optic nerves and optic chiasm. In addition, they may encase major blood vessels, thus compromising the possibility for total resection. So one of the main aims of surgery is to relief the optic apparatus compression, allowing for visual recovery [25] [34]. Improvement in vision has been reported in $40 \%$ to $80 \%$ of patients undergoing surgery [6] [10] [25] [33] [34]. No change in visual status has been reported in $18 \%$ to $40 \%$, whereas worsened vision has been reported in $17 \%$ to $20 \%$ [10] [26]. In this series there were 17 patients diagnosed with tuberculum sellae meningiomas who underwent surgical removal over a 4 -year period. The mean follow-up duration was 12 months. Visual acuity improved in 8 patients 
(47\%), remained unchanged in 7 patients (41\%), and worsened in one patient (5.9\%) of patients.

\subsection{Extent of Tumor Resection}

A review of old the literature, there is a stress on that complete tumor resection should not be achieved at the cost of increased rates of morbidity, especially the risk of visual deterioration and hypothalamic dysfunction [9] [24] but in recent microsurgical series, there were high rates of complete tumor resection ranged from $35 \%$ to $100 \%$. The extent of tumor resection has improved with the advent of modern microsurgery [1] [5] [17].

In our series, there was only 3 patients patients (18\%) in whom there was subtotal resection of a meningioma was achieved, residual tumor in the two cases were related to either the carotid artery or anterior cerebral artery that were very adherent to these vessels, for which a more aggressive dissection and resection was judged to be injurious. The third case subtotal resction was considered due to a calcified portion of the lesion extending toward the brainstem that could not be removed. The percentage of Gross total resection in this series is about $82 \%$.

\section{Conclusion}

Transcranial removal of tuberculum sellae meningioma is still considered the standard approach for this type of lesions even after advancement of extended endoscopic skull base approaches, with high rate of gross total resection and better hemostasis of the tumor bed.

\section{Recommendations}

A comparative study between endoscopic endonasal extended approach and transcranial approach is needed.

\section{Limitations}

Small number of the study and relatively short follow up period.

\section{Conflicts of Interest}

The authors state no conflict of interests.

\section{References}

[1] Al-Mefty, O. and Smith, R.R. (1991) Tuberculum sellae Meningiomas. In: Al-Mefty, O., Ed., Meningiomas, Raven Press, Ltd., New York, 395-411.

[2] Cushing, H. and Eisenhardt, L. (1938) Suprasellar Meningiomas, in Meningiomas: Their Classification, Regional Behaviour, Life History, and Surgical End Results. Charles C. Thomas, Springfield, 224-249.

[3] Giammattei, L., Starnoni, D., Cossu, G., Bruneau, M., Cavallo, L.M., Cappabianca, P., et al. (2020) Surgical Management of Tuberculum sella Meningiomas: Myths, Facts, and Controversies. Acta Neurochirurgica, 162, 631-640. 
https://doi.org/10.1007/s00701-019-04114-w

[4] Jane, J.A. and McKissock, W. (1962) Importance of Failing Vision in Early Diagnosis of Suprasellar Meningiomas. BMJ, 2, 5-7. https://doi.org/10.1136/bmj.2.5296.5

[5] Al-Mefty, O., Holoubi, A., Rifai, A. and Fox, J.L. (1985) Microsurgical Removal of Suprasellar Meningiomas. Neurosurgery, 16, 364-372. https://doi.org/10.1227/00006123-198503000-00014

[6] Ajlan, A.M., Choudhri, O., Hwang, P. and Harsh, G. (2015) Meningiomas of the Tuberculum and Diaphragma Sellae. Journal of Neurological Surgery Part B, 76, 74-79. https://doi.org/10.1055/s-0034-1390400

[7] Brihaye, J. and Brihaye-van Geertruyden, M. (1988) Management and Surgical Outcome of Suprasellar Meningiomas. Proceedings of the 8 th European Congress of Neurosurgery, Barcelona, 6-11 September 1987, 124-129. https://doi.org/10.1007/978-3-7091-8975-7_25

[8] Ciric, I. and Rosenblatt, S. (2001) Suprasellar Meningiomas. Neurosurgery, 49, 1372-1377. https://doi.org/10.1097/00006123-200112000-00014

[9] Ehlers, N. and Malmros, R. (1973) The Suprasellar Meningioma. A Review of the Literature and Presentation of a Series of 31 Cases. Acta Ophthalmologica. Supplementum, 1-74.

[10] Fahlbusch, R. and Schott, W. (2002) Pterional Surgery of Meningiomas of the Tuberculum sellae and Planum sphenoidale: Surgical Results with Special Consideration of Ophthalmological and Endocrinological Outcomes. Journal of Neurosurgery, 96, 235-243. https://doi.org/10.3171/jns.2002.96.2.0235

[11] Grkovic, D. and Davidovic, S. (2016) Prognostic Factors for Postoperative Visual Outcome in Surgically Treated Suprasellar Meningiomas. Medicinski Pregled, 69, 146-152 https://doi.org/10.2298/MPNS1606146G

[12] Holmes, G. and Sargent, P. (1927) Suprasellar Endotheliomata. Brain, 50, 518-537. https://doi.org/10.1093/brain/50.3-4.518

[13] Jallo, G.I. and Benjamin, V. (2002) Tuberculum Sellae Meningiomas: Microsurgical Anatomy and Surgical Technique. Neurosurgery, 51, 1432-1440.

[14] Jefferson, A. and Azzam, N. (1979) The Suprasellar Meningiomas: A Review of 19 Years' Experience. Acta Neurochirurgica Supplementum, 28, 381-384.

[15] Ohta, K., Yasuo, K., Morikawa, M., Nagashima, T. and Tamaki, N. (2001) Treatment of Tuberculum sellae Meningiomas: A Long-Term Follow-Up Study. Journal of Clinical Neuroscience, 8, 26-31. https://doi.org/10.1054/jocn.2001.0873

[16] Ray, B.S. (1968) Intracranial Hypophysectomy. Journal of Neurosurgery, 28, 180-186. https://doi.org/10.3171/jns.1968.28.2.0180

[17] Rosenstein, J. and Symon, L. (1984) Surgical Management of Suprasellar Meningioma. Part 2: Prognosis for Visual Function Following Craniotomy. Journal of Neurosurgery, 61, 642-648. https://doi.org/10.3171/jns.1984.61.4.0642

[18] Simpson, D. (1957) The Recurrence of Intracranial Meningiomas after Surgical Treatment. Journal of Neurology, Neurosurgery \& Psychiatry, 20, 22-39. https://doi.org/10.1136/jnnp.20.1.22

[19] Arai, H., Sato, K., Okuda, O., Miyajima, M., Hishii, M., Nakanishi, H. and Ishii, H. (2000) Transcranial Transsphenoidal Approach for Tuberculum sellae Meningiomas. Acta Neurochirurgica, 142, 751-757. https://doi.org/10.1007/s007010070089

[20] Finn, J.E. and Mount, L.A. (1974) Meningiomas of the Tuberculum Sellae and Planum Sphenoidale. A Review of 83 Cases. Archives of Ophthalmology, 92, 23-27. https://doi.org/10.1001/archopht.1974.01010010027007 
[21] Gregorius, F.K., Hepler, R.S. and Stern, W.E. (1975) Loss and Recovery of Vision with Suprasellar Meningiomas. Journal of Neurosurgery, 42, 69-75. https://doi.org/10.3171/jns.1975.42.1.0069

[22] Halves, E. and Vogt, H. (1975) Proceedings: Meningiomas of the Sellar Region. Acta Neurochirurgica, 31, 280-281.

[23] Khalafallah, A.M., Rakovec, M., Burapachaisri, K., Fung, S., et al. (2021) The Suprasellar Meningioma Patient-Reported Outcome Survey: A Disease-Specific PatientReported Outcome Measure for Resection of Suprasellar Meningioma. Journal of Neurosurgery, 1-9. https://doi.org/10.3171/2021.6.JNS21517

[24] Olivecrona, H. (1967) The Suprasellar Meningiomas. In: Olivecrona, H. and Tönnis, W., Eds., Handbuch der Neurochirurgie, Springer-Verlag, Berlin, 167-172.

[25] Chicani, C.F. and Miller, N.R. (2003) Visual Outcome in Surgically Treated Suprasellar Meningiomas. Journal of Neuro-Ophthalmology, 23, 3-10. https://doi.org/10.1097/00041327-200303000-00002

[26] Magill, S.T., Morshed, R.A., Lucas, C.G., Aghi, M.K., Theodosopoulos, P.V., Berger, M.S., et al. (2018) Tuberculum sellae Meningiomas Grading Scale to Assess Surgical Outcomes Using the Transcranial versus Transsphenoidal Approach. Neurosurg Focus, 44, E9. https://doi.org/10.3171/2018.1.FOCUS17753

[27] Karsy, M., Raheja, A., Eli, I., Guan, J. and Couldwell, W.T. (2017) Clinical Outcomes with Transcranial Resection of the Tuberculum Sellae Meningioma. World Neurosurgery, 108, 748-755. https://doi.org/10.1016/j.wneu.2017.09.090

[28] Kuga, D., Toda, M. and Yoshida, K. (2018) Treatment Strategy for Tuberculum Sellae Meningiomas Based on a Preoperative Radiological Assessment. World Neurosurg, 120, e1279-e1288. https://doi.org/10.1016/j.wneu.2018.09.054

[29] Gray, H. (1985) Anatomy of the Human Body. 30th Edition, Lea \& Febiger, Philadelphia.

[30] Xiao, F., Shen, J., Zhang, L., Yang, J., Weng, Y., Fang, Z., Zhang, C., Ye, H., Zhan, R. and Zheng, X. (2021) Unilateral Subfrontal Approach for Giant Tuberculum Sellae Meningioma: Single Center Experience and Review of the Literature. Frontiers in Oncology, 11, Article ID: 708235. https://doi.org/10.3389/fonc.2021.708235

[31] Conforti, P., Moraci, A., Albanese, V., Rotondo, M. and Parlato C (1991) Microsurgical Management of Suprasellar and Intraventricular Meningiomas. Minimally Invasive Neurosurgery, 34, 85-89. https://doi.org/10.1055/s-2008-1052061

[32] Chan, R.C. and Thompson, G.B. (1984) Morbidity, Mortality, and Quality of Life Following Surgery for Intracranial Meningiomas. A Retrospective Study in 257 Cases. Journal of Neurosurgery, 60, 52-60. https://doi.org/10.3171/jns.1984.60.1.0052

[33] Cushing, H. and Eisenhardt, L. (1929) Meningiomas arising from the tuberculum sellae: With the Syndrome of Primary Optic Atrophy and Bitemporal Field Defects Combined with a Normal Sellae Turcica in a Middle-Aged Person. Archives of Ophthalmology, 1, 1-41. https://doi.org/10.1001/archopht.1929.00810010004001

[34] Grant, F.C. (1953) Meningiomas of Tuberculum Sellae. American Journal of Ophthalmology, 36, 715-717. 